\title{
The best predictor of anxiety, stress, and depression among institutionalized elderly
}

\author{
Ni Putu Wulan Purnama Sari ${ }^{1}$, Maria Manungkalit ${ }^{2}$ \\ ${ }^{1}$ Department of Palliative Nursing, Widya Mandala Catholic University Surabaya, Indonesia \\ ${ }^{2}$ Department of Medical-Surgical Nursing, Widya Mandala Catholic University Surabaya, Indonesia
}

\begin{tabular}{l}
\hline \hline Article Info \\
\hline Article history: \\
Received Agt 21, 2019 \\
Revised Oct 28, 2019 \\
Accepted Nov 11, 2019 \\
\hline
\end{tabular}

Keywords:

Anxiety

Depression

Elderly

Predictor

Stress

\begin{abstract}
Anxiety, stress, and depression are the three most common negative emotional constructs found in the elderly. Evidences available worldwide about how psychological problem could be resulted in mental disorder, and there is significant difference in the context of living in the nursing home and in community setting. This study aimed to determine the best predictor of anxiety, stress, and depression in elderly living in the nursing home, useful for future modification and intervention development. This cross-sectional study involved 145 elderly in a private nursing home in Surabaya, Indonesia. HARS, SPST-20, and GDS were used in data collection. Linear regression and one way ANOVA tests were used in data analysis $(\alpha<0.05)$. Results showed that mostly in old individuals, mild anxiety and stress, and undepressed state were found. Sensory problems and concentration difficulties were the best predictor of anxiety and stress respectively, which were accounted for $61.2 \%$ and $65.6 \%$ variances of anxiety and stress in nursing home residents respectively. Spirits, life energy, happiness, and feeling wonderful to be alive could not predict depression significantly. Feeling inferior to others is the best predictor of depression, which was accounted for $25.9 \%$ variance of depression in this population. Low self-esteem leads to depression in nursing home residents.
\end{abstract}

Copyright (c) 2019 Institute of Advanced Engineering and Science. All rights reserved.

\section{Corresponding Author:}

Ni Putu Wulan Purnama Sari,

Department of Palliative Nursing, Widya Mandala Catholic University Surabaya,

Jl. Raya Kalisari Selatan 1, Pakuwon City, Surabaya 60112, Indonesia.

Email: wulanpurnama@ukwms.ac.id

\section{INTRODUCTION}

The global issue of ageing population in various parts of the world has raised a great concern towards the high-prevalence mental disorders or psychological problem in elderly [1]. Psychological problems that are often found in the elderly are anxiety, stress, and depression [2]. These three problems are considered as the negative emotional contructs [3]. Evidences showed that there was a significant difference regarding the prevalence of psychiatric disorders between long term care setting and community setting, in which those disorders are more common in the long term care setting [4]

Depression, the most prevalent mental health problem found in elderly, cause an elevation in morbidity and mortality rate, a decrease in quality of life (QOL), and an increase in health care costs [5]. The widespread high prevalence of depression in the nursing homes is not always followed by an appropriate concern from the health care professionals in the field, so that the utilization of depression screening test is highly recommended in this setting [6]. Depression is a serious mental health problem involving symptoms related to mood, cognitive, and physical symptoms, influenced by various factors (biological, physical, psychological, and social); often occurs in the elderly due to lack of support systems, age-related factors, factors of education level, health status and lack of activity [7]. 
Anxiety is an emotional condition that causes discomfort, characterized by feelings of worry, anxious, and fear, often occurs in the elderly as a result of various changes experienced by the aging process [8]. Anxiety is more prevalent in elderly with disability, and being a significant predictor of progressing disability, cognitive impairment, and nursing home placement [9]. Anxious depression, a state in which anxiety co-morbid with depression, is correlated with severe symptoms \& impairments, poorer prognosis, increases suicide risk in elderly [9]. Results of a systematic review towards 74 studies showed that depression and anxiety are the most common psychiatric disorders among older adults living in long-term care facility [4]. Hamilton [10], a senior research fellow, the developer of worldwide-used Hamilton Anxiety Rating Scale (HARS), stated that low or high level of anxiety is found in agitated depression, obsessional state, organic dementia, hysteria, and schizophrenia [10]. Anxiety, together with depression, worry, and social fear could result in generalized anxiety disorder, especially in older adults [11].

The father of stress research, Hans Selye, who focused on universal patient reactions to illness, stated that stress is a nonspecific response of the body to any demand [12]. He also stated that every stress leaves an indelible scar, and the organism pays for its survival after a stressful situation by becoming a little older. Stress causes pressure, change, and emotional tension; characterized by the feeling of angry, anxious, sad, pessimistic, crying, irritable, having nightmares, impaired concentration and memory; often occurs in the elderly due to the common problems related to declining physical health, low and declining functions in daily living and cognition [13-14]. Institutionalized elderly experienced higher distress and had lower life satisfaction compared to those living in the community [9]. The utilization of a standardized general distress screening test could improve the accuracy of detection and diagnosis of an anxiety or a depressive disorder among elderly who receive home care [9]; which indicates that the presence of distress leads to the incidence of anxiety and depression, especially in community-dwelling elderly.

Anxiety, stress, and depression, have significant impact on elderly's QOL, therefore these three variables become very important to be assessed regularly. There is a significant relationship between anxiety and depression levels with QOL in the elderly who live in nursing homes $[8,15]$; and there is a significant relationship between stress levels and QOL in the elderly, especially in those with chronic disease, such as hypertension and diabetes mellitus [16-17]. This study aimed to determine the best predictor of anxiety, stress, and depression in elderly living in the nursing home, useful for future modification and intervention development. By knowing the best predictor of anxiety, stress, and depression in elderly living in the nursing home, it will be useful for future modification and intervention development, especially in nursing context, with the ultimate goal of QOL optimization in the late life.

\section{RESEARCH METHOD}

This cross-sectional study involved 145 elderly in a private nursing home in Surabaya, Indonesia. Inclusion criteria wereat least 60 years old, and having a family member as the one responsible for elderly care in the nursing home to be the contact person. Exclusion criteria were rejection on filling out the consent form, hospitalization, and impaired consciousness or disorientation. Total sampling was applied and sample size of 145 was obtained. Instrument of Hamilton Anxiety Rating Scale (HARS) [10], Suan Prung Stress Test-20 (SPST-20) [18], and Geriatric Depression Scale (GDS) [19] were used to collect the data of anxiety, stress, and depression respectively. Data were collected since February-May 2019. Linear regression and one way ANOVA tests were used in data analysis $(\alpha<0.05)$. Ethical clearance was issued by Faculty of Medicine, Widya Mandala Catholic University Surabaya, Indonesia, with certificate number of 010/WM12/KEPK/T/2019.

HARS is used to assess the severity of anxiety in both clinical and research settings in many parts of the world since the old times until recently, so that this instrument is really popular for decades worldwide. HARS consists of 14 items which defined by a series of symptoms measuring both psychic anxiety (mental agitation and psychological distress) and somatic anxiety (physical complaints related to anxiety). Each item is scored on Likert scale of " 0 " (not present) to "4" (severe), with a total score range of 0-56, in which less than 17 indicates mild severity, 18-24 indicates mild to moderate severity, and 25-30 indicates moderate to severe level of anxiety [10].

SPST was developed by Thai researcher and made specifically for assessing stress level in Thai population. SPST consists of 20 items in which each item is scored on Likert scale of "0" (no stress) to "4" (extremely high stress), with a total score range of 0-80, in which 0-23 indicates mild stress, 24-41 indicates moderate stress, 42-61 indicates high stress, and more than 61 indicates severe stress [18]. SPST-20 has been tested for validity and reliability in elderly communities in Surabaya with good results (IOC=0.78; Cronbach's Alpha=0.94) [20]. GDS consists of 15 items rated on a dichotomy response: "Yes" or "No". The score was one point for each one selected by respondents. A score of 0 to 5 is normal or undepressed state, while a score greater than 5 suggests depression. Reviews validation studies of GDS

Int. J. Public Health Sci. Vol. 8, No. 4, Dec 2019: 419-426 
indicated that it is a promising tool for detecting depression in the elderly. Evidence showed that GDS is a valid and reliable instrument for testing depression in elderly, and also sensitive for a special condition like dementia and other physical ilness [21].

\section{RESULTS AND DISCUSSIONS}

There were 145 elderly participated in this study. Most of them were old individuals (75-90 years old), female, married, Chinese, secondary school graduated, and living in the nursing home for 1-3 years. Table 1 explains the demography characteristic of study respondents in details.

Table 1. Demography characteristic

\begin{tabular}{|c|c|c|c|}
\hline No. & Characteristic & Frequency & Percentage $(\%)$ \\
\hline \multirow{5}{*}{1} & Age (years old) & & \\
\hline & a. Pre-elderly (45-59) & 9 & 6.20 \\
\hline & b. Elderly (60-74) & 65 & 44.82 \\
\hline & c. Old $(75-90)$ & 68 & 46.89 \\
\hline & d. Very old (>90) & 3 & 2.06 \\
\hline \multirow{3}{*}{2} & Gender & & \\
\hline & a. Male & 71 & 48.96 \\
\hline & b. Female & 74 & 51.03 \\
\hline \multirow{5}{*}{3} & Marital status & & \\
\hline & a. Single & 33 & 22.75 \\
\hline & b. Married & 58 & 40.00 \\
\hline & c. Separated / divorced & 9 & 6.20 \\
\hline & d. Widowed & 45 & 31.03 \\
\hline \multirow{5}{*}{4} & Ethnicity & & \\
\hline & a. Javanese & 55 & 37.93 \\
\hline & b. Maduranese & 10 & 6.89 \\
\hline & c.. Chinese & 76 & 52.41 \\
\hline & d. Others & 4 & 2.75 \\
\hline \multirow{6}{*}{5} & Educational background & & \\
\hline & a. Primary school & 29 & 20.00 \\
\hline & b. Secondary school & 50 & 34.48 \\
\hline & c. High school & 44 & 30.34 \\
\hline & d. University graduated & 19 & 11.03 \\
\hline & e. Uneducated & 3 & 2.06 \\
\hline \multirow{5}{*}{6} & Period of living in nursing home (years) & & \\
\hline & a. $<1$ & 33 & 22.75 \\
\hline & b. $1-3$ & 59 & 40.68 \\
\hline & c. $>3-6$ & 41 & 28.27 \\
\hline & d. $>6$ & 12 & 8.27 \\
\hline
\end{tabular}

Results of descriptive statistic showed that averagely respondents had mild anxiety (Mean \pm SD: 16.78 \pm 13.69 ), mild stress (Mean \pm SD: 23.14 \pm 15.18 ), and not depressed (Mean \pm SD: 16.78 \pm 13.69$)$. Table 2 explains the reported data of anxiety, stress, and depression in details.

Table 2. Measured variables

\begin{tabular}{cccc}
\hline No. & Variables \& levels & Frequency & Percentage (\%) \\
\hline \multirow{4}{*}{$1 \quad$ Anxiety } & 93 & 64.1 \\
& a. Mild severity & 30 & 20.7 \\
& b. Mild to moderate severity & 22 & 15.2 \\
c. Moderate to severe & & \\
Stress & 81 & 55.9 \\
2 & a. Mild stress & 47 & 32.4 \\
& b. Moderate stress & 16 & 11.0 \\
c. High stress & 1 & 0.7 \\
d. Severe stress & & \\
& Depression & 50 & 34.5 \\
& a. Normal (undepressed state) & 95 & 65.5 \\
& b. Depressed & &
\end{tabular}

Regression test results showed that all items in HARS and SPST-20 could predict anxiety and stress significantly $($ all $p<\alpha$ ), but sensory problem and concentration difficulties were proved to be the best predictor of anxiety and stress respectively. Sensory problem was accounted for $61.2 \%$ variance of anxiety in elderly living in the nursing home $(\mathrm{p}=0.000)$, while concentration difficulties were accounted for $65.6 \%$ 
variance of stress in this population $(\mathrm{p}=0.000)$. Feeling inferior to others was proved to be the best predictor of depression, and it was accounted for $25.9 \%$ variance of depression, while spirits, life energy, happiness, and feeling wonderful to be alive could not significantly predict depression in this population (all $\mathrm{p}>\alpha$ ). Table 3 shows the results of regression test in details.

Table 3. Results of statistical analysis

\begin{tabular}{ccccc}
\multicolumn{5}{c}{ (a) Predictors of Anxiety } \\
\hline No. & Determinant & R square & \% of influence & SIG. \\
\hline 1 & Anxious mood & 0.495 & 49.5 & .000 \\
2 & Tension & 0.305 & 30.5 & .000 \\
3 & Fears & 0.461 & 46.1 & .000 \\
4 & Insomnia & 0.467 & 46.7 & .000 \\
5 & Intellectual & 0.526 & 52.6 & .000 \\
6 & Depressed mood & 0.473 & 47.3 & .000 \\
7 & Somatic (muscular) & 0.485 & 48.5 & .000 \\
$\mathbf{8}$ & Somatic (sensory) & $\mathbf{0 . 6 1 2}$ & $\mathbf{6 1 . 2}$ & $\mathbf{. 0 0 0}$ \\
9 & Cardiovascular symptoms & 0.403 & 40.3 & .000 \\
10 & Respiratory symptoms & 0.487 & 48.7 & .000 \\
11 & Gastrointestinal symptoms & 0.517 & 51.7 & .000 \\
12 & Genitourinary symptoms & 0.485 & 48.5 & .000 \\
13 & Autonomic symptoms & 0.498 & 49.8 & .000 \\
14 & Behavior at interview & 0.576 & 57.6 & .000 \\
\hline
\end{tabular}

(b) Predictors of stress

\begin{tabular}{ccccc}
\hline No. & Determinant & R square & \% of influence & SIG. \\
\hline 1 & Anxious of making mistakes & 0.132 & 13.2 & .000 \\
2 & Anxious of failing in reaching the goals & 0.269 & 26.9 & .000 \\
3 & Financial problems & 0.327 & 32.7 & .000 \\
4 & Anxious about pollution & 0.480 & 48.0 & .000 \\
5 & Competitiveness and comparisons in life & 0.483 & 48.3 & .000 \\
6 & Money shortages & 0.414 & 41.4 & .000 \\
7 & Muscle pains & 0.425 & 42.5 & .000 \\
8 & Tension headache & 0.455 & 45.5 & .000 \\
9 & Back pains & 0.444 & 44.4 & .000 \\
10 & Appetite loss & 0.491 & 49.1 & .000 \\
11 & Migraine & 0.563 & 56.3 & .000 \\
12 & Feeling worried & 0.420 & 42.0 & .000 \\
13 & Feeling frustrated & 0.503 & 50.3 & .000 \\
14 & Feeling angry & 0.551 & 55.1 & .000 \\
15 & Feeling sad & 0.538 & 53.8 & .000 \\
16 & Memory problems & 0.586 & 58.6 & .000 \\
17 & Confusion & 0.606 & 60.6 & .000 \\
$\mathbf{1 8}$ & Concentration difficulties & $\mathbf{0 . 6 5 6}$ & $\mathbf{6 5 . 6}$ & $\mathbf{. 0 0 0}$ \\
19 & Easily tired & 0.472 & 47.2 & .000 \\
20 & Frequent cold & 0.385 & 38.5 & .000 \\
\hline
\end{tabular}

\begin{tabular}{ccccc}
\multicolumn{5}{c}{ (c) Predictors of depression } \\
\hline No. & Determinant & R square & \% of influence & SIG. \\
\hline 1 & Life satisfaction & 0.052 & 5.2 & .006 \\
2 & Dropping activities and interests & 0.199 & 19.9 & .000 \\
3 & Life emptiness & 0.154 & 15.4 & .000 \\
4 & Boringness & 0.096 & 9.6 & .000 \\
5 & Spirits & 0.013 & - & .164 \\
6 & Fear of bad things & 0.170 & 17.0 & .000 \\
7 & Happiness & 0.002 & - & .616 \\
8 & Feeling helpless & 0.192 & 19.2 & .000 \\
9 & Prefer staying at home & 0.075 & 7.5 & .000 \\
10 & Memory problems & 0.246 & 24.6 & .000 \\
11 & Feeling wonderful to be alive & 0.001 & - & .756 \\
12 & Feeling worthless & 0.165 & 16.5 & .000 \\
13 & Full of energy & 0.010 & - & .226 \\
14 & Hopeless situation & 0.255 & 25.5 & .000 \\
$\mathbf{1 5}$ & Feeling inferior to others & $\mathbf{0 . 2 5 9}$ & $\mathbf{2 5 . 9}$ & $\mathbf{. 0 0 0}$ \\
\hline
\end{tabular}

There are various levels of anxiety, stress, and depression found in study respondents. Therefore, the best predictor of level differences of each variable was also identified. One way ANOVA test results showed that all items in HARS and SPST-20 could significantly predict anxiety and stress levels respectively $($ all $\mathrm{p}<\alpha)$; while in depression, there were four items in GDS which could not significantly predict 
the depression levels in elderly living in the nursing home, such as: item 5 about spirits $(\mathrm{p}=0.667)$, item 7 about happiness ( $\mathrm{p}=0.851)$, item 11 about feeling wonderful to be alive $(\mathrm{p}=0.861)$, and item 13 about life energy $(\mathrm{p}=0.379)$.

Depression, stress, and anxiety could affect QOL, suicide, physical problems, and socioeconomic status in elderly, in which these three negative emotional constructs were associated with demographic variables like sex, education, marital status, medical condition, and housing conditions [22]. Female gender and lower educational background had higher values of anxiety and depression [23]. In this study, we found more married female than male elderly with low educational background, but overall mild anxiety and stress with undepressed state were found in majority. The anxiety disorders are a prevalent mental health problem in older age; it has a particular co-morbidity and risk factor profile [24]. Aside from demographic variables, anxiety disorders in the elderly were also associated with neurotic personality trait, cognitive decline, frailty, impaired physical function, disability, and increased medications intake [25-26].

Results showed that mental agitation, psychological distress, and physical complaints related to anxiety could predict anxiety (psychic and somatic) significantly in elderly living in the nursing home, as shown in Table 3A that all predictors were accounted for a certain number of anxiety variance in study respondents. Sensory problems (physical complaints related to somatic anxiety) were proved to be the best predictor of anxiety in this study context. Sensory problems could happen in various part of the body, and sensory impairment in older adults can increase their probability of experiencing depressive and anxiety syndrome. A study towards 7,389 Italian elderly showed that vision and hearing impairments are associated with depressive-anxiety syndrome, in which higher anxiety syndrome prevalence found in the hearing impaired group compared to higher depressive syndrome prevalence found in the vision-impaired group [27]. Vision and hearing impairments in the elderly which often called dual sensory loss (DSL: combined vision and hearing loss) was associated with decreased mental health significantly, with those with DSL either displaying depressive symptoms or being at risk for developing depression [28].

Hearing loss, the most common sensory deficit in the elderly, could impair the exchange of information which significantly influences activity of daily living resulted in loneliness, isolation, dependence, frustration, and communication disorders [29]. A study towards 42 elderly hearing impaired patients showed that mild anxiety was correlated with self-reported hearing problems, but depression was strongly related to self-perceived hearing handicap [30]. Another study towards 15 individuals aged more than 70 years old with hearing loss and depressive mood showed that reduction in depressive symptoms and improved QOL were observed early on with the use of digital hearing aids, and mental health also changed for the better [31]. Escape/avoidance coping strategies is associated with anxiety sensitivity in the elderly, but the fact found in another study towards 94 elderly showed that elderly with hearing problems did not use escape/avoidance coping strategies, therefore they were not sensitive to anxiety [32]. The results of these studies contradict the above study results from Bernabei, et al. (2011) [27] which found that the hearing-impaired elderly are more susceptible to anxiety syndrome than depression. But, all studies agree that hearing problems are resulted in psychological problems in the elderly.

Anxiety could influence stress level in elderly because of its effect on physical function in everyday life [20]. Medical issues were the most common stressors for elderly living in the nursing home, and elderly copes frequently by praying, reading, watching television, listening to music, and talking to friends and family [33]. There was negative correlation found between psychological problems and coping strategies in elderly living in the nursing home, meaning if their coping increases then psychological problems decreases [34]. Relocation to a nursing home from community setting could be a stressor also for the elderly, often called as relocation stress syndrome (RSS), in which transitional care is needed [35]. RSS has some clinical manifestations, such as anxiety, confusion, hopelessness, and loneliness, which usually diagnosed in the elderly right after a short period of staying in the nursing home after long time living in a private residence [36]. Transitional care in nursing homes frequently faces problems associated with adjustment by elderly residents [35].

Results showed that physical and psychological responses towards various stressors could predict stress significantly in elderly living in the nursing home, as shown in Table 3B that all predictors were accounted for a certain number of stress variance in study respondents. Concentration difficulties were proved to be the best predictor of stress in this study context. Concentration is the ability to maintain attention in a longer period. One of acute stress reaction is concentration disorder [37]. A study towards 74 elderly showed that the presence or absence of cognitive impairment may result in chronic stress and coping strategies, in which memory deficit may be a risk factor of high stress level [38]. Concentration disorder may affect stress level in elderly because of its effect on cognitive function impairment [20].

The study about association between concentration difficulties and stress, especially in elderly, is very limited online. Most articles available online correlate concentration difficulties with post-traumatic stress disorder (PTSD), but not with age-related changes induced stress found in the elderly. For instance, 
a study towards elderly (veteran) with PTSD and sleep disturbance found that marked differences were observed for symptoms such as anxiety, self-depreciation, guilt, and concentration difficulties [39].

In the other context, a study towards 45 adults with mobile phone-related symptoms (headaches, earache, warmth sensations, fatigue, and perceived concentration difficulties) showed that concentration difficulties, together with sensations of warmth and burning skin, could increase the levels of exhaustions and depression, but not of anxiety, stress, and somatization [40]. Still in the other context, a study towards college students showed that academic stress was correlated with cognitive deficits, such as attention and concentration difficulties, illness, anxiety, depression, and low life satisfaction [41]. Both studies showed some connection of stress and concentration difficulties. Further study in elderly, especially nursing home residents, need to be conducted in order to determine the theoretical mechanism of both variables' connection.

Psychological distress could result in depression in aging population. In physical context, a study towards 73,131 individuals aged 20-100 years old showed that the mechanism of psychological distress becoming depression is mediated by the elevated level of C-Reactive Protein (CRP) in the blood. Increased CRP levels are associated with high risk of psychological distress and depression in most individuals [42]. It is indicated that the psychological distress could induce the elevation of CRP levels so that it could result in depression. In social context, a study in Japanese rural communities showed that psychological distress was higher in groups with low social capital measured by trust (lower), than groups with high social capital; indicating pathways existed from social capital to psychological distress via supportive relationships [43]. Social capital is the summary of shared norms, values, beliefs, trust, networks, social relations, and institutions which modulated cooperation and collective action for mutual benefit; structure \& cognitive, bonding, bridging, and linking, strong \& weak; and horizontal \& vertical for instance [44]. It is indicated that the psychological distress induced by lower trust from others resulted in low social capital leading to depression in the elderly.

Results showed that spirits, life energy, happiness, and feeling wonderful to be alive could not predict depression significantly in this study context, which is contradict the study results of Sheikh \& Yesavage [21]. Feeling inferior to others were proved to be the best predictor of depression, which was accounted for $25.9 \%$ variance of depression in this study context. The inferior feeling towards others indicated low self-esteem in study respondents. Self-esteem is defined as "how we value our self"; it affects our trust and relationships in every part of life [45]. Low self-esteem refers to a reflection of central negative views about self and it is important not only for elderly, but also for adults and children [46]. Depression could cause by low self-esteem which is frequently found in the elderly in various country [47]. Person with low self-esteem may feel powerless and incompetent about himself/herself. A qualitative study towards nursing home residents showed that depression is common among elderly which attributed to low self-esteem [48]. Therefore, low self-esteem leads to depression in nursing home residents.

There are so many aspects in comparison if someone wants to compare himself with the others. Physical appearance, physical capabilities, vocational and recreational interests, and relationships are all defining aspects of one's identify. For instance, social comparison addresses the damage to self-worth and the restoration of self-esteem following chronic illness in elderly. Individual living with chronic illness could restore his self-esteem by modifying three primary mechanism of social comparison, denial, and deriving meaning from the experience. Although social comparison provides an opportunity to increase self-esteem, the extent to which someone engages in social comparison actually may represent greater psychological distress [49].

Anxiety, stress, and depression represent the existence of mental distress in elderly living in the nursing home. Nurses work in this setting need to periodically assess the level of these three variables in order to improve the residents' QOL, and further giving interventions. As stated in the background, by knowing this study results it will be useful for future modification and intervention development. Nursing interventions could be ranging from physically-targeted intervention to spiritually-targeted intervention. Orientation program-based intervention which proved to be effective for managing these three problems [50]. Spiritual-religion psychotherapy which proved to be effective for improving depression especially [51]. Neslihan suggested to improve physical activity in the elderly in order to manage depression in the elderly. Further implementation of aforementioned interventions in the local context of elderly living in the nursing home in Surabaya should be cautioned [52].

\section{CONCLUSION}

All determinants in HARS and SPST-20 were proved to be significant predictors of anxiety and stress in elderly living in the nursing home. Sensory problems and concentration difficulties are the best predictor of anxiety and stress respectively, which were accounted for $61.2 \%$ and $65.6 \%$ variances of anxiety 
and stress in this population. There are four determinants in GDS which were not proved to be significant predictors of depression, namely: spirits, life energy, happiness, and feeling wonderful to be alive. Feeling inferior to others is the best predictor of depression, which was accounted for $25.9 \%$ variance of depression in this study context. Low self-esteem leads to depression in nursing home residents.

\section{ACKNOWLEDGEMENTS}

This study was supported for publication by Faculty of Nursing, Widya Mandala Catholic University Surabaya.

\section{REFERENCES}

[1] G. J. Byrne, N. A. Pachana, “Anxiety and Depression in the Elderly: Do We Know Any More?," Current Opinion in Psychiatry, vol.23, no.6, pp. 504-509, 2010.

[2] M. Stanley, P. G. Beare, "Textbook of Gerontology Nursing (in Bahasa Indonesia)," Jakarta: EGC, 2006.

[3] B. M. Wood, M. K. Nicholas, F. Blyth, A. Asghari, S. Gibson, "The utility of The Short Version of The Depression Anxiety Stress Scales (DASS-21) in Elderly Patients with Persistent Pain: Does Age Make a Difference?,"Pain Medicine, vol.11, no.12, pp. 1780-1790, 2010.

[4] D. Seitz, N. Purandare, D. Conn, "Prevalence of Psychiatric Disorders among Older Adults in Long-Term Care Homes: A Systematic Review," International Psychogeriatric, vol.22, no.7, pp. 1025-1039, 2010.

[5] S. Kumar, K. R. Adiga, A. George, "Impact of Mindfulness-Based Stress Reduction (MBSR) on Depression among Elderly Residing in Residential Homes," The Nursing Journal of India, vol.105, pp.6, pp. 248-251, 2014.

[6] J. Snowdon, "Depression in Nursing Homes," International Psychogeriatrics, vol.22, no.7, 1143-1148, 2010.

[7] K. Pae, "Differences of Depression Level between Elderly Lives in The Nursing Home and at Home with Families (in Bahasa Indonesia)," Jurnal Ners Lentera, vol.5, no.1, 21-32, 2017.

[8] E. Setyaningsih, Setiyawan, Saelan, "Correlation between Anxiety and Quality of Life in Nursing Home of Dharma Bhakti Kasih, Surakarta (in Bahasa Indonesia)," $2017 . \quad$ Retrieved from: http://digilib.stikeskusumahusada.ac.id/repo/disk1/29/01-gdl-endangsety-1443-1-naskahp-h.pdf

[9] G. J. Diefenbach, D. F. Tolin, S. A. Meunier, C. M. Gilliam, "Assessment of Anxiety in Older Home Care Recipients," The Gerontologist, vol.49, no.2, pp. 141-153, 2009.

[10] M. Hamilton, "The Assessment of Anxiety States by Rating," Br J Med Psychol, vol.32, pp. 50-55, 1959.

[11] J. G. Beck, M. A. Stanley, "Characteristics of Generalized Anxiety Disorder in Older Adults: A Descriptive Study," Behaviour Research and Therapy, vol.34, no.3, pp. 225-234, 1996.

[12] S. Y. Tan, A. Yip, "Hans Selye (1907-1982): Founder of The Stress Theory," Singapore Med J, vol.59, no.4, pp. 170-171, 2018.

[13] N. Muramatsu, H. Yin, D. Hedeker, "Functional Declines, Social Support, and Mental Health in the Elderly: Does Living in a State Supportive of Home and Community-Based Services Make a Difference?,"Social Science \& Medicine, vol.70, no.7, pp. 1050-1058, 2010.

[14] M. M. Koampa, H. Bidjuni, F. Onibala, "Correlation between Stress Level and Independency Level in Elderly, Tombasian Village, West Kawangkoan District (in Bahasa Indonesia)," eJournal Keperawatan (e-Kp), vol.3, no.2, pp. 1-6, 2015.

[15] A. A. A. R. Puspadewi, E. Rekawati, "Depression is Associated with Quality of Life in The Nursing Home of Tresna Werdha, Jakarta (in Bahasa Indonesia),"Jurnal Keperawatan Indonesia, vol.20, no.3, pp. 133-138, 2017.

[16] Azizah, "The 4 University Research Coloquium 2016," 2016. Retrieved from: https://publikasiilmiah.ums.ac.id/bitstream/handle/11617/7766/Mahasiswa\%20(Student\%20Paper\%20Presentation) (1)_31.pdf?sequence=1

[17] M. Zainuddin, W. Utomo, Herlina, "Correlation between Stress and Quality of Life in Type 2 Diabetes Mellitus (in Bahasa Indonesia),"JOM, vol.2, no.1, pp. 890-898, 2015.

[18] S. Mahatnirankul, V. Pumpaisanchai, P. Tapanya, "The Construction of Suan Prung Stress Test for Thai Population,"Bulletin of Suan Prung, vol.13, no.3, pp. 1-11, 1997.

[19] J. A. Yesavage, T. L. Brink, T. L. Rose, O. Lum, V. Huang, M. Adey, V. O. Leirer, "Development and Validation of a Geriatric Depression Screening Scale: A Preliminary Report," J Psychiatr Res., vol.17, no.1, pp. 37-49, 1982.

[20] N. P. W. P. Sari, J. Artsanthia, "Comparison of Stress Level and Quality of Life in Elderly Who are Living with Chronic Illness in Bangkok and Surabaya," Proceedings of the $9^{\text {th }}$ International Nursing Conference (INC 2018), pp. 101-109, 2018.

[21] J. I. Sheikh, J. A. Yesavage, "Geriatric Depression Scale (GDS): Recent Evidence and Development of A Shorter Version," Clinical Gerontologist: The Journal of Aging and Mental Health, vol.5, no.1-2, pp. 165-173, 1986.

[22] T. Babazadeh, R. Sarkhoshi, F. Bahadori, F. Moradi, F. Shariat, Y. Sherizadeh, "Prevalence of Depression, Anxiety and Stress Disorders in Elderly People Residing in Khoy, Iran (2014-2015)," J Anal res Clin Med, vol.4, no.2, pp. 122-128, 2016.

[23] C. M. Teixeira, J. Vasconcelos-Raposo, H. M.Fernandes, R. J. Brustad, "Physical Activity, Depression and Anxiety among the Elderly,"Soc Indic Res, vol.113, pp. 307-318, 2013.

[24] M. B. Sami, R. Nilforooshan, "The Natural Course of Anxiety Disorders in the Elderly:A Systematic Review of Longitudinal Trials,"International Psychogeriatrics, vol.27, no.7, pp. 1061-1069, 2015. 
[25] C. R. Gale, A. A. Sayer, C. Cooper, E. M. Dennison, J. M. Starr, L. J. Whalley, J. E. Gallacher, Y. Ben-Shlomo, D. Kuh, R. Hardy, L. Craiq, I. J. Deary, HALCyon Study Team,"Factors Associated with Symptoms of Anxiety and Depression in Five Cohorts of Community-Based Older People: The HALCyon (Healthy Ageing Across The Life Course) Programme,"Psychological Medicine, vol.41, pp. 2057-2073, 2011.

[26] A. M. Ní Mhaoláin, C. W. Fan, R. Romero-Ortuno, C. Cunningham, R. A. Kenny, B. Lawlor, "Frailty, Depression, and Anxiety in Later Life,"International Psychogeriatrics, vol.24, pp. 1265-1274, 2012.

[27] V. Bernabei, V. Morini, F. Moretti, A. Marchiori, B. Ferrari, E. Dalmonte, D. De Ronchi, A. R. Atti, "Vision and Hearing Impairments are Associated with Depressive-Anxiety Syndrome in Italian Elerly," Aging \& Mental Health, vol.15, no.4, pp. 467-474, 2011.

[28] C. Heine, C. J. Browning, "Mental Health and Dual Sensory Loss in Older Adults: A Systematic Review," Frontiers in Aging Neuroscience, vol.6, no.83, pp. 1-9, 2014.

[29] A. Ciorba, C. Bianchini, S. Pelucchi, A. Pastore, "The Impact of Hearing Loss on the Quality of Life of Elderly Adults," Clin Interv Aging, vol.7, pp.159-163, 2012.

[30] G. Andersson, M. Green, "Anxiety in Elderly Hearing Impaired Persons," Perceptual and Motor Skills, vol.81, no.2, pp. 552-554, 1995.

[31] R. Boi, L. Racca, A. Cavallero, V. Carpaneto, M. Racca, F. D. Acqua, M. Ricchetti, A. Santelli, P. Odetti, "Hearing Loss and Depressive Symptoms in Elderly Patients," Geriatrics Gerontology International, vol.12, no.3, pp.440445,2012

[32] G. Andersson, C. Hagnebo, "Hearing Impairment, Coping Strategies, and Anxiety Sensitivity," Journal of Clinical Psychology in Medical Settings, vol.10, no.1, pp.35-39, 2003.

[33] I. R. Hunter, M. C. Gillen, "Stress Coping Mechanisms in Elderly Adults: An Initial Study of Recreational and Other Coping Behaviors in Nursing Home Patients," Adultspan Journal, vol.8, no.1, pp. 43-53, 2009.

[34] R. Nishanthi, R. Priya, "Level of Psychological Problems and Coping Strategies of Elderly Persons Residing in Old Age Homes," International Journal of Pharmaceutical and Clinical Research, vol. 9, no.10, pp. 660-664, 2017.

[35] G. E. Lee, "Predictors of Adjustment to Nursing Home Life of Elderly Residents: A Cross-Sectional Survey," International Journal of Nursing Studies, vol.47, no.8, pp. 957-964, 2010.

[36] C. A. Walker, L. C. Curry, M. O. Hogstel, "Relocation Stress Syndrome in Older Adults Transitioning from Home to A Long-Term Care Facility: Myth or Reality," J Psychosoc Nurs Ment Health Serv, vol.45, no.1, pp. 38-45, 2007.

[37] M. F. Idrus, "Stress-related disorder (in Bahasa Indonesia)," 2016. Retrieved from: http://med.unhas.ac.id/kedokteran/wp-content/uploads/2016/10/Gangguan-Terkait-dengan-Stres.pdf

[38] J. N. Souza-Talaricoa, E. C. Chaves, R. Nitrini, P. Caramellic, "Chronic Stress is Associated with High Cortisol Levels and Emotional Coping Mechanisms in Amnestic Mild Cognitive Impairment,"Dement Geriatr Cogn Disord, vol.28, pp. 465-470, 2009.

[39] J. Guerrero, M-A. Crocq, "Sleep Disorders In The Elderly: Depression And Post-Traumatic Stress Disorder," Journal of Psychosomatic Research, vol.38, no.1, pp. 141-150, 1994.

[40] A. Johansson, S. Nordin, M. Heiden, M. Sandstrom, "Symptoms, personality traits, and stress in people with mobile phone-related symptoms and electromagnetic hypersensitivity," Journal of Psychosomatic Research, vo.68, no.1, pp. 37-45, 2010.

[41] R. R. Brougham, C. M. Zail, C. M. Mendoza, J. R. Miller, "Stress, Sex Differences, and Coping Strategies among College Students," Current Psychology, vol.28, no.2, pp. 85-97, 2009.

[42] M. K. Wium-Andersen, D. D. Orsted, S. F. Nielsen, B. G. Nordestgaard, "Elevated C-Reactive Protein Levels, Psychological Distress, and Depression in 73,131 Individuals," JAMA Psychiatry, vol.70, no.2, pp. 176-184, 2013.

[43] T. Hamano, M. Yamasaki, Y. Fujisawa, K. Ito, T. Nabika, K. Shiwaku, "Social Capital and Psychological Distress of Elderly in Japanese Rural Communities," Stress \& Health, vol.27, no.2, pp. 163-169, 2011.

[44] H. Bhandari, K. Yasunobu, "What Is Social Capital? A Comprehensive Review of the Concept," Asian Journal of Social Science, vol.37, no.3, pp. 480-510, 2009.

[45] R. F. Baumeister, "Self-Esteem: The Puzzle of Low Self-Regard," 1993. New York: Springer, USA.

[46] A. E. Steiger, M. Allemand, R. W. Robins, H. A. Fend, "Low and Decreasing Self-Esteem During Adolescence Predict Adult Depression Two Decades Later,"J PersSocPsychol, vol.106, pp. 325-338, 2014.

[47] U. Orth, R. W. Robins, K. H. Trzesniewski, J. Maes, M. Schmitt, "Low Self-Esteem is a Risk Factor for Depressive Symptoms from Young Adulthood to Old Age,"J AbnormPsychol, vol.118, pp. 472-478, 2009.

[48] S. A. Ali, N. Suhail, S. A. Ali, "Low Self-Esteem Leads to Depression among Elderly: Case Study of Nursing Home," Journal of Universal Surgery, vol.4, no.2(52), pp. 1-4, 2016.

[49] S. Robinson-Whelen, K. J. K. Kiecolt-Glaser, R. Glaser, "Effect of Chronic Stress on Immune Function and Health in the Elderly," Behavior, Health, and Aging, vol.6, pp. 14, 2014.

[50] M. Piadehkousar, F. Ahmadi, M. F. Khoshknab, A. Rasekhi, "The Effect of Orientation Program Based on the Activities of Daily Living on Stress, Anxiety and Depression in the Elderly," International Journal of Community Based Nursing and Midwifery, vol.7, no.3, pp. 170-180, 2019.

[51] S. S. Ghotbabadi, K. H. Alizadeh, "The Effectiveness of Spiritual-Religion Psychotherapy on Mental Distress (Depression, Anxiety and Stress) in the Elderly Living in Nursing Homes," Health, Spirituality and Medical Ethics, vol.5, no.1, pp. 20-25, 2018.

[52] L. Neslihan, L. Sefa, C. Muammer, "The Effect of Physical Activity on Depression Symptoms and Quality of Life among Elderly Nursing Home Residents: Randomized Controlled Trial," Archives of Gerontology and Geriatrics, vol.70, pp. 92-98, 2017.

Int. J. Public Health Sci. Vol. 8, No. 4, Dec 2019: 419-426 